\title{
Schmerzgedächtnis muss überschrieben werden
}

_ Die wiederholte Aktivierung durch schmerzhafte Reize führt an den Nervenzellen zu molekularen Veränderun-

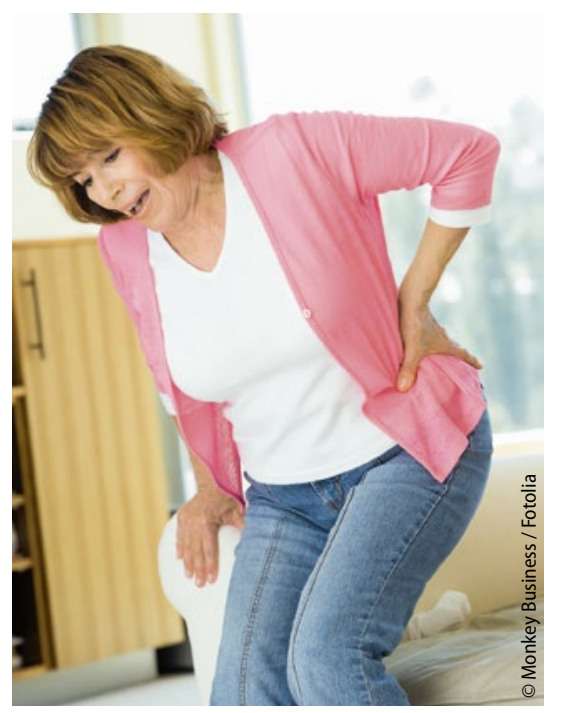

Ihr hilft nur ein multimodaler Ansatz! gen. Wie Prof. Walter Zieglgänsberger, München, erläuterte, entwickelt sich eine gesteigerte Schmerzempfindlichkeit, respektive ein Schmerzgedächtnis, nicht nur auf Basis einer verringerten Reizschwelle der Nozizeptoren (primäre Hyperalgesie), sondern auch durch neuroplastische Veränderungen im Zentralnervensystem mit zellulärer Hyperaktivität auf Rückenmarksebene (sekundäre Hyperalgesie).

An der Entstehung des Schmerzgedächtnisses sind u. a. das Mittelhirn, thalamische, limbische und kortikale Strukturen beteiligt sowie die Nervenzellen selbst, die in ihren Dendriten und Spines die Informationen durch Modulation der synaptischen Übertragung speichern. Im Rahmen des Schmerz-Lernprozesses kommt es in der Nervenzelle zu einer De-novo-Proteinsynthese, die das morphologische Korrelat des Schmerzgedächtnisses darstellt.
Die Therapie chronischer Schmerzen wird dadurch erschwert, dass das Gehirn keine Löschtaste hat, so Zieglgänsberger. Chronischer Schmerz sei kein andauernder Akutschmerz, sondern die Folge einer nozizeptiven Aktivierung.

Analgetika lindern nur akuten Schmerz, für chronischen Schmerz existiert kein spezifisches Medikament. Vielmehr erfordert er eine multimodale Schmerztherapie aus medikamentösen und psychotherapeutischen Maßnahmen, die durch neuen „Input“ zu Re-Learning mit Überschreibung des Schmerzgedächtnisses mit positiven Erfahrungen führt. Damit könnten Vermeidungsverhalten, Schonhaltung oder Inaktivität reduziert und die körperliche Aktivität gefördert werden.

Dagmar Jäger-Becker

- Kongress „Praxisnah"; Frankurt, November 2017 (Veranstalter: Hexal)

\section{Antibiotikainduzierte Diarrhö}

\section{Multispezies-Probiotikum schützt Darmflora}

_ Das Mikrobiom im Magen-DarmTrakt spielt eine wichtige Rolle in der menschlichen Physiologie. Die Darmbakterien schützen vor einer Überwucherung durch pathogene Keime und modulieren das Immunsystem sowohl in der Darmschleimhaut als auch systemisch.

Bei einer Therapie mit Antibiotika kommt es zur nachhaltigen Störung dieses Mikrobioms. Die daraus resultierende Dezimierung des positiven mikrobiellen Keimspektrums schwächt die Mukosabarriere. Dies kann eine sogenannte antibiotikaassoziierte Diarrhö (AAD) auslösen, die von milden, nicht therapiepflichtigen Formen bis hin zur lebensbedrohlichen Clostridien-induzierten pseudomembranösen Kolitis variiert.

Seit etwa einem Jahrzehnt weiß man, dass Probiotika eine zerstörte Darmflora wiederherstellen können. Von entscheidender Bedeutung ist jedoch die Zusammensetzung der verwendeten Bakterienstämme. Speziell zur Behandlung der AAD wurde das Multispezies-Probiotikum Innovall ${ }^{\circledast}$ Microbiotic AAD entwickelt. Es besteht aus zehn Bakterienstämmen in hoher Dosierung.

In einer randomisierten, placebokontrollierten Doppelblindstudie wurde die Wirkung eines Probiotikums, das wie Innovall ${ }^{\oplus}$ Microbiotic AAD zusammengesetzt ist, auf die metabolische Darmflora, das Stuhlverhalten und die Aktivierung des mukosalen Immunsystems untersucht. Wie sich zeigte, wurden Diarrhö und antibiotikaassoziierte Nebenwirkungen in der Verumgruppe signifikant reduziert (48\% vs. 79\%). Es kam zu einer Stimulation des mukosalen Immunsys- tems (evident durch einen Anstieg von sekretorischem IgA im Serum) sowie zu einem messbaren Anstieg exakt jener Bakterien, die mit dem Probiotikum zugeführt wurden [Koning CJ et al. Am J Gastroenterol. 2008;103:178-89].

In einer Beobachtungsstudie mit 200 Patienten, die an einer antibiotikapflichtigen Infektion litten, wurde das Probiotikum gemeinsam mit dem jeweils notwendigen Antibiotikum verabreicht. Es kam zu keiner Unverträglichkeit, und nur ein Patient klagte nach zehn Tagen Therapie über Durchfall. Die Autoren schätzen die Gabe des Probiotikums zur Vermeidung einer AAD als extrem erfolgreich ein [J Gastroenterol Hepatol Erkr. 2009;7(4):38-41].

Red. 